\title{
Synthesis of Lauric-Myristic Acid/Activated Carbon Composite as a New Shape- Stabilized Energy Storage Material
}

\author{
Yanghua CHEN*, Minrong GE, Feng ZHAO, Xue YANG \\ School of Mechatronics Engineering, Nanchang University, Nanchang 330031, China \\ crossref http://dx.doi.org/10.5755/j02.ms.26840
}

Received 26 June 2020; accepted 06 August 2020

\begin{abstract}
In this work, a new composite phase change material (CPCM) with lauric-myristic acid (LA-MA) eutectic as PCM and activated carbon (AC) was used as supporting material with four different mass ratios of 5.0:5.0, 5.5:4.5, 6.0:4.0, and $6.5: 3.5$, respectively. The properties and microstructure of LA-MA/AC were analyzed by some characterization methods. The results show that the composite process of LA-MA eutectic and AC was a simple physical mixing and no new chemical bonds were found. The fusion and freeze temperature, enthalpy of the samples were measured by differential scanning calorimetry (DSC), and the residual weight of the samples was analyzed by thermogravimeter (TGA). It was shown that the fusion and freeze temperature of LA-MA eutectic separately were $32.42{ }^{\circ} \mathrm{C}$ and $33.63{ }^{\circ} \mathrm{C}$, and its fusion enthalpy and freeze enthalpy were $152.64 \mathrm{~J} / \mathrm{g}$ and $148.8 \mathrm{~J} / \mathrm{g}$, respectively. TGA data shows that the thermal stability of LA-MA eutectic was obviously improved by adding AC as a support material. The results of this study can be available for reference to solar energy storage applications.

Keywords: lauric-myristic eutectic, compound materials, activated carbon, phase change materials.
\end{abstract}

\section{INTRODUCTION}

The concept of latent heat storage is to use materials to absorb or release the enthalpy of phase change during the phase transition, and it has the characteristics of high energy storage density and almost no temperature fluctuation in the process of releasing thermal energy. Among its four phase change forms, solid-liquid phase change materials (SLPCMs) have a relatively higher enthalpy than solidsolid, and the volume change is smaller than solid-gas and gas-liquid PCM. Therefore, it has been widely concerned in recent years.

SLPCMs can be divided into two types: inorganic and organic materials, according to the composition of different chemical elements. Inorganic materials have the advantage of high thermal conductivity, good flame retardancy and high volumetric energy storage density [1]. It has obvious drawbacks that cannot be ignored, such as supercooling, phase separation and violent corrosivity, which limit the energy conversion in time. Organic materials have the advantage of low toxicity, low corrosion, economy and no phase separation compare to inorganic materials, and it can be used for energy storage systems with low melting temperature $\left(<150^{\circ} \mathrm{C}\right)$ [1]. Organic materials have been designed for textiles [2], cold storage [3], building materials $[4,5]$, solar energy storage $[6,7]$, lithium batteries $[8,9]$, waste heat recovery $[10,11]$, air conditioning [12], etc. At the same time, organic materials (paraffin, fatty acids, eutectic materials, etc.) have the phenomenon of leakage and low heat exchange coefficient in the process of phase transformation. In the past, researchers had developed many methods to combine it with support materials to manufacture shape-stabilized composite PCM (CPCM) to overcome these shortcomings.

\footnotetext{
${ }^{*}$ Corresponding author. Tel.: +86-13970944938;

E-mail address: 545422685@qq.com (Y. Chen)
}

At present, several supporting materials that have received much attention include expanded graphite (EG) [3,13-15], carbon nanotubes (CNT) [16, 17], expanded perlite (EP) [18, 19], activated carbon (AC) [20-22], expanded vermiculite (EVT) [23] and graphite nanoplate (Gr) [24]. Su et al [25] studied n-octadecane/stearic acid (SA-ODE) eutectic mixture as PCM and hexagonal boron nitride (HBN) was served as support material to manufacture CPCM. It was concluded that the optimal ratio was the SA-ODE eutectic with $10 \% \mathrm{HBN}$, and the heat exchange coefficient is increased by $8.0 \%$ when the temperature was $20^{\circ} \mathrm{C}$. Kim et al. [14] studied the octadecane (OD)/WEPG composite PCM prepared by using the kneader mixing technology to absorb OD as an energy storage material into the support material WEPG; the results indicate that when the WEPG content in the OD/WEPG composite exceeds $30 \%$, it keeps the form stable during the temperature rises from 23 to $80^{\circ} \mathrm{C}$. Ince et al. [24] prepared a myristic acid (MA)/Gr composite material using MA as a thermal energy conversion carrier and $\mathrm{Gr}$ was served as a matrix material; their finding when the content of $\mathrm{Gr}$ in composite PCM at $2 \%$, the thermal conductivity increased $38 \%$. Hu et al. [20] investigated 1-Hexadecanol-Palmitic acid (HD-PA)/AC composite developed by vacuum impregnation; the conclusion was that the heat exchange coefficient and thermal stability of the composites were enhanced. Putra et al. [16] synthesized beeswax/multi-wall CNTs composite PCM by the impregnation method; they found that adding multi-wall CNTs can improve the thermal performance and stability of solid and liquid beeswax.

In this work, the eutectic mixture of lauric-myristic acid (LA-MA) is selected as PCM due to relatively high enthalpy and low price, $\mathrm{AC}$ is used as support material with abundant 
micro-pore structures, huge specific surface area, low density and good thermal conductivity [20]. Four CPCM were fabricated with the ratio of LA-MA eutectic and AC at 5:5, 5.5:4.5, 6:4, and 6.5:3.5, respectively. The properties and microstructures of LA-MA/AC were analyzed by some characterization methods, and the compositions of LA-MA and AC was verified by the analysis of the chemical structure.

\section{EXPERIMENTAL}

\subsection{Materials}

Lauric acid $\left(\mathrm{C}_{12} \mathrm{H}_{24} \mathrm{O}_{2}\right.$, AR, pure $\left.>99 \%\right)$, activated carbon (AC, > 200 mesh), and myristic acid $\left(\mathrm{C}_{14} \mathrm{H}_{28} \mathrm{O}_{2}, \mathrm{AR}\right.$, pure $\geq 99 \%$ ) were obtained from Shanghai Aladdin Biochem Technology Co., Ltd. Eutectic of lauric-myristic acid (LA-MA) was used as a heat storage material.

\subsection{Synthesis of LA-MA eutectic}

According to the eutectic theory, LA and MA were blended to form a eutectic material. The eutectic point of LA-MA can be estimated by Schroder's theoretical equation $[26,27]$ :

$$
T=\frac{1}{\left(\frac{1}{T_{i}}-\frac{R \ln x_{i}}{\Delta H_{i}}\right)}
$$

where $T$ represent melting point of eutectic, $\mathrm{R}$ stands for gas constant. $T_{i}, x_{i}$ and $\Delta H_{i}$ separately represent melting temperature, molar fraction and enthalpy of component $i$.

Based on formula (1), the molar ratio of LA and MA was calculated at 6.51:3.49. To facilitate mass weighing, the molar ratio was converted into mass ratio, which was determined at 62:38. The mixture that weights $10 \mathrm{~g}$ with mass ratio 62:38 for LA and MA is poured into a $500 \mathrm{ml}$ beaker, which placed in a thermostatic magnetic stirring water bath at $70^{\circ} \mathrm{C}$ and heated until the mixture completely melted. Then, the mixture was stirred at $600 \mathrm{rpm} / \mathrm{min}$ for $1 \mathrm{~h}$ to guarantee the mixing uniformity with the constant temperature.

\subsection{Preparation of LA-MA/AC composite}

In this work, four kinds of CPCM with different composite ratios were prepared by using $\mathrm{AC}$ as the matrix material and LA-MA eutectic as PCM. The specific composition ratio of CPCMs are listed in Table 1. Before mixing, the weighted AC was placed in an air-circulation oven at $70^{\circ} \mathrm{C}$ for $16 \mathrm{~h}$ to remove the moisture from the porous matrix materials. Then, the dried porous material was placed in a molten eutectic mixture, during which the temperature was maintained at $70{ }^{\circ} \mathrm{C}$, and the rotation speed was maintained at $600 \mathrm{rpm} / \mathrm{min}$ and stirred uniformly for 1 hour to a homogeneous mixture. Finally, The CPCMs were placed in a dry oven at $33^{\circ} \mathrm{C}$ for $48 \mathrm{~h}$, so that the water evaporates and obtained dried CPCMs.

In order to obtain a shape-stable composite with a high phase change enthalpy, CPCMs were put in an aircirculation oven at $50{ }^{\circ} \mathrm{C}$ and heated for 1 h. In Fig. 1, it was found that the weight percentage of LA-MA eutectic in sample was more than $55 \%$, which was caused by liquid phase leakage.
Table 1. The mass ratio of different CPCM

\begin{tabular}{|c|c|c|c|c|}
\hline Samples & LA, g & MA, g & AC, g & $\begin{array}{c}\text { Mass ratio of } \\
\text { LA-MA/AC }\end{array}$ \\
\hline CPCM1 & 6.20 & 3.80 & 10.00 & $50: 50$ \\
\hline CPCM2 & 6.20 & 3.80 & 8.20 & $55: 45$ \\
\hline CPCM3 & 6.20 & 3.80 & 6.70 & $60: 40$ \\
\hline CPCM4 & 6.20 & 3.80 & 5.40 & $65: 35$ \\
\hline
\end{tabular}
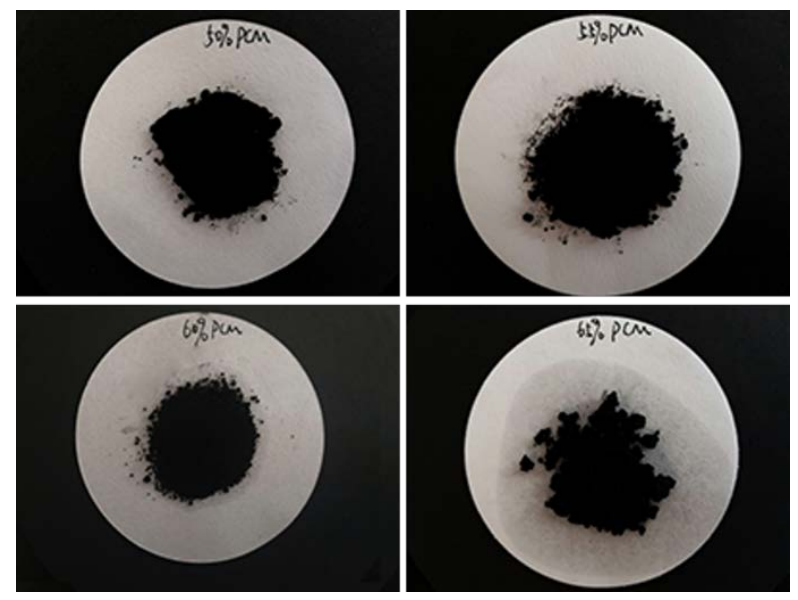

Fig. 1. The leak test of CPCMs with different LA-MA content

\subsection{Characterization and properties of CPCMs, AC and LA-MA eutectic}

The chemical structures of CPCMs, LA-MA eutectic and $\mathrm{AC}$ were determined by Fourier transformation infrared spectrometer (FT-IR, Nicolet5700, spectra range from $4000 \sim 400 \mathrm{~cm}^{-1}$, resolution using $\mathrm{KBr}$ pellets). All CPCM samples and AC were treated by gold spraying under vacuum to observe their micro-structure by scanning electron microscope (SEM, JSM6701F). The crystalline phase of CPCMs, LA-MA eutectic, and AC were analyzed by $\mathrm{X}$-ray diffractometer (XRD, D8) within angle range of $10-60^{\circ}$ with a speed of $2 \theta(5 \% \mathrm{~min})$. The enthalpy and melting-solidifying temperature of the LA-MA/AC were analyzed by differential scanning calorimetry (DSC, DSC 8500) within the temperature range of $-10-90^{\circ} \mathrm{C}$ at the temperature change of $5{ }^{\circ} \mathrm{C} / \mathrm{min}$ under a continuous nitrogen flow. The residual weight of the CPCMs was tested by thermogravimetric analysis (TGA, TGA 4000) at room temperature to $700{ }^{\circ} \mathrm{C}$ under the condition of continuous nitrogen flow and a heating rise of $20^{\circ} \mathrm{C} / \mathrm{min}$.

\section{RESULTS AND DISCUSSION}

\subsection{Analysis chemical structure by FT-IR spectrum}

Fig. 2 shows the FT-IR spectra of LA-MA eutectic, AC, and CPCM1-CPCM4. The LA-MA eutectic spectrum shows that there are several main bands at $2917 \mathrm{~cm}^{-1}$, $2845 \mathrm{~cm}^{-1}, 1697 \mathrm{~cm}^{-1}, 1471 \mathrm{~cm}^{-1}, 1302 \mathrm{~cm}^{-1}, 983 \mathrm{~cm}^{-1}$, and $716 \mathrm{~cm}^{-1}$. The characteristic spectral bands corresponding to the symmetric and antisymmetric stretching vibration of $-\mathrm{CH}_{3}$ and $-\mathrm{CH}_{2}$ chemical bonds appear at $2917 \mathrm{~cm}^{-1}$ and $2845 \mathrm{~cm}^{-1}[17,28]$. The absorption spectral band at $1697 \mathrm{~cm}^{-1}$ is produced by stretching vibration of $\mathrm{C}=\mathrm{O}$ bonds. The spectral band at $1471 \mathrm{~cm}^{-1}$ represents the deformation vibration of $-\mathrm{CH}$ in $-\mathrm{CH}_{2}$ [29]. The in-plane 
deformation vibration and out of plane deformation vibration of $-\mathrm{OH}$ functional group results in the characteristic spectral bands at $1302 \mathrm{~cm}^{-1}$ and $983 \mathrm{~cm}^{-1}$ [30]. The spectral band at $716 \mathrm{~cm}^{-1}$ is caused by the swinging vibration of $-\mathrm{CH}_{2}$ group. The characteristic spectral band at $1583 \mathrm{~cm}^{-1}$ corresponds to the stretching vibration of $\mathrm{C}=\mathrm{C}$ bonds. The FT-IR spectra of CPCM1-4 have all absorption spectral bands of binary eutectic acid and the band of AC at $1583 \mathrm{~cm}^{-1}$. The results show that the composite process of LA-MA eutectic and AC was a simple physical mixing and no new chemical bonds were found.

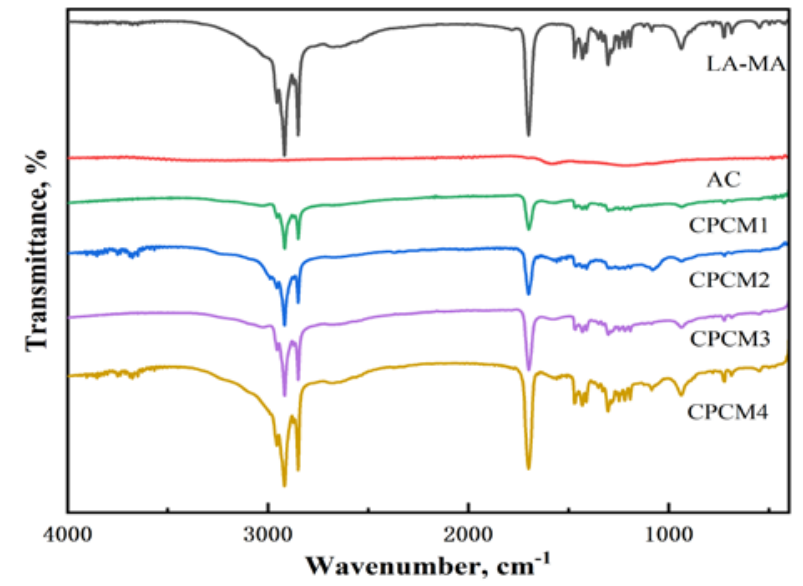

Fig. 2. FT-IR spectra of LA-MA eutectic, AC, CPCM1, CPCM2, CPCM3 and CPCM4

\subsection{Analysis of LA-MA/AC by XRD patterns}

The XRD curves of LA-MA eutectic mixture, AC, CPCM1, CPCM2, CPCM3 and CPCM4 are shown in Fig. 3.

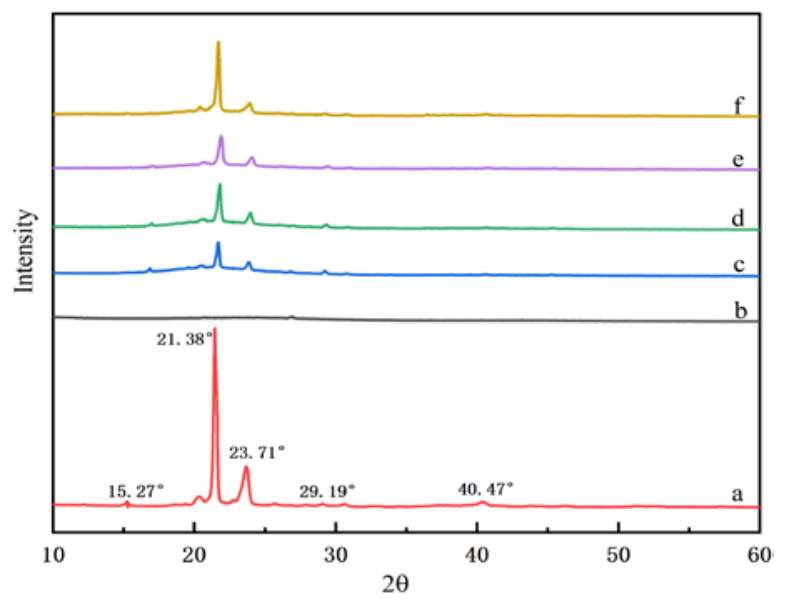

Fig. 3. XRD curves: a-LA-MA eutectic; b-AC; c-CPCM1; d-CPCM2; e-CPCM3; f-CPCM4

The Fig. 3 a presents the XRD pattern of LA-MA eutectic. The curves show that the five intensive peaks of LA-MA eutectic at $15.27^{\circ}, 21.38^{\circ}, 23.71^{\circ}, 29.19^{\circ}, 40.47^{\circ}$, respectively. The XRD pattern of AC is shown in Fig. $3 \mathrm{~b}$. It indicates that AC has no obvious crystal peaks, so AC is an amorphous structure. Fig. $3 \mathrm{c}-\mathrm{f}$ presents the XRD curves of CPCM1, CPCM2, CPMC3 and CPCM4. It can be seen that the four composite PCMs still retain the crystal structure at the same position. It was concluded that the crystal structure of LA-MA eutectic remains during the synthesis, and no new atomic groups are generated.

\subsection{Micromorphology analysis of the LA-MA/AC}

SEM graphs of morphology of LA-MA eutectic, AC, CPCM1, CPCM2, CPCM3 and CPCM4 are shown in Fig. 4. Fig. $4 \mathrm{a}$ and Fig. $4 \mathrm{f}$ separately present the microstructure image of AC and LA-MA eutectic. It can be observed that the AC has an abundant multi-layered structure and highly porous structure. The comparison between Fig. 4 b, c and Fig. 4 a shows that the AC retains the layered structure and its surface becomes smoother, which shows that the eutectic acid is well absorbed into pore structure due to the effect of surface interaction forces and pore forces. Comparing Fig. 4 d, e and Fig. 4 b, c, it is found that c has completely covered the pore structure of the AC and overflowed on the surface. The comparative analysis shows that the content of LA-MA eutectic in the composite is $55 \%$, which is the most stable composite.

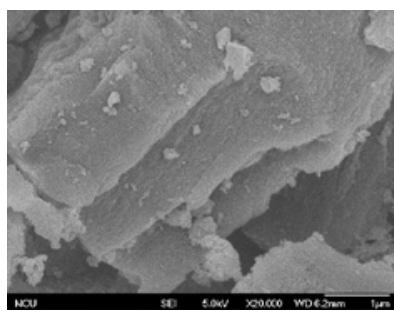

a

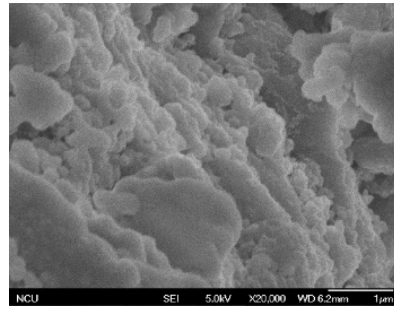

C

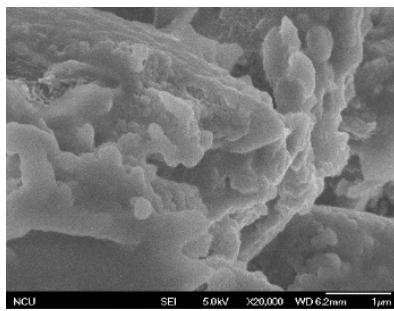

e

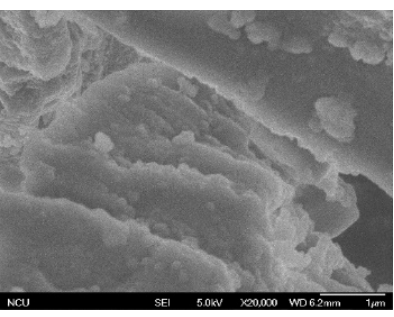

b

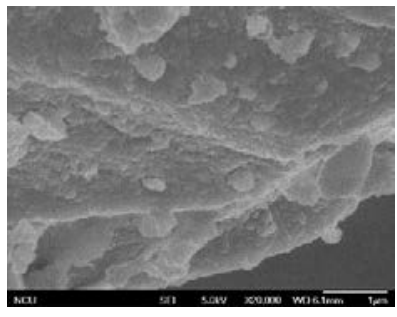

d

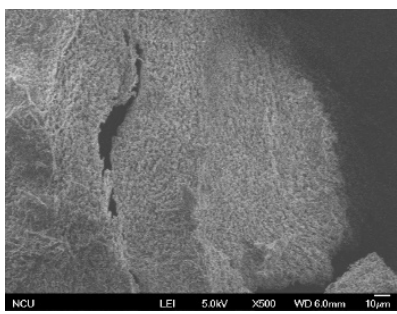

f
Fig. 4. SEM graphs: a - AC; b-CPCM1; c-CPCM2; d-CPCM3; e-CPCM4; f-LA-MA eutectic.

\subsection{The DSC date analysis of CPCMs}

The DSC results of the LA-MA eutectic and LAMA/AC composites are shown in Fig. 5 and Fig. 6. The onset temperature, the peak temperature, enthalpy of fusion and freeze enthalpy are shown in Table 2. It is found in Table 2 that the fusion and freeze temperatures from CPCM1 to CPCM4 reduce as the addition of AC decreases. It may be that the force of LA-MA is enhanced with the load of AC increasing, which impacts on the phase transition process further. The supercooling degree of CPCM1-4 is $0.37{ }^{\circ} \mathrm{C}, 0.36^{\circ} \mathrm{C}, 0.32^{\circ} \mathrm{C}$, and $0.27^{\circ} \mathrm{C}$, respectively. The reasons are cause by the AC can prevent the perfect crystallization of pure LA-MA. 
Fig. 5 and Fig. 6 illustrate that LA-MA eutectic and CPCM samples only have a peak, indicating that only solidliquid phase transition during the phase change.

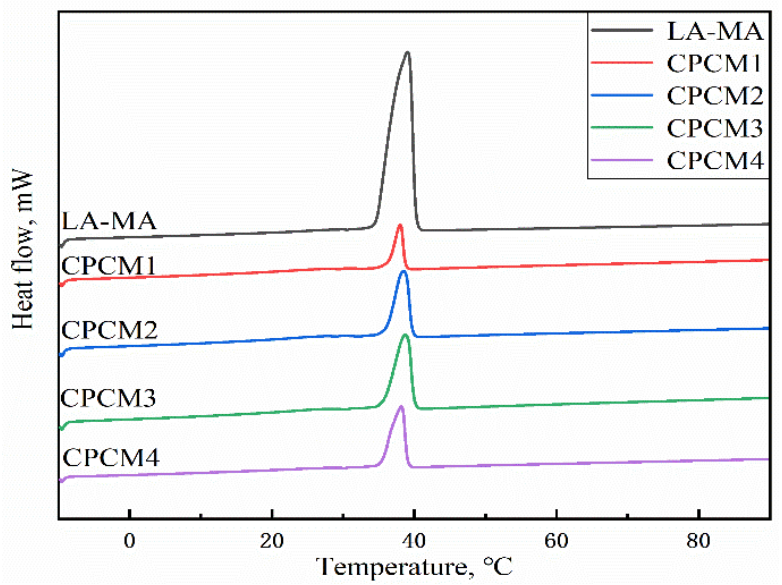

Fig. 5. Melting DSC curves of LA-MA eutectic and LA-MA/AC composites

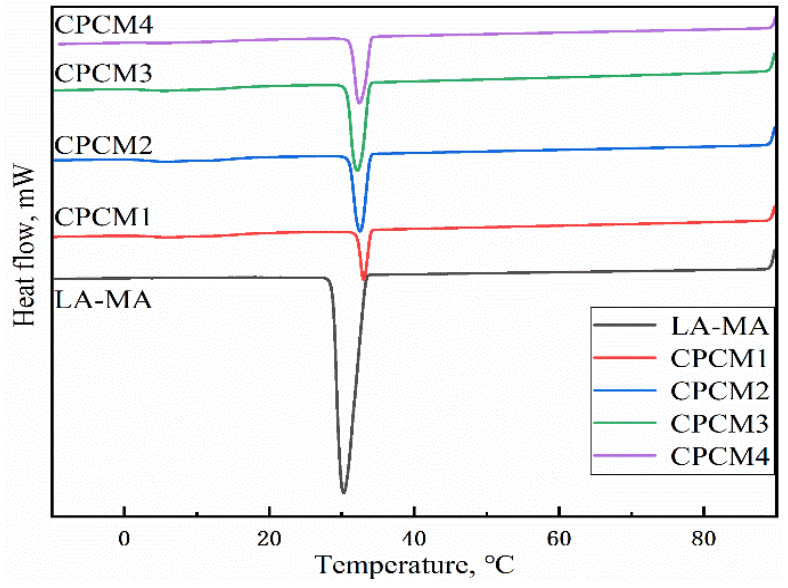

Fig. 6. Solidifying DSC curves of LA-MA eutectic and LAMA/AC composites

The phenomenon indicates that the addition of AC did not change the energy exchange mode of PCM. The enthalpy of CPCMs in Table 2 verifies that the enthalpy increases with the proportion of LA-MA eutectic increases. Therefore, only the LA-MA eutectic in the composites undergoes a phase transition to convert thermal energy. Based on DSC data, the best composite ratio can be selected. It is found that the melting enthalpy $(61.67 \mathrm{~J} / \mathrm{g})$ and solidification enthalpy (56.82 J/g) of CPCM4 are higher than those of the other three. However, when the weight proportion of LA-MA in the composite was more than $55 \%$, there was liquid phase leakage. Therefore, the CPCM2 is the best composite with melting and freezing temperature are $34.77^{\circ} \mathrm{C}$ and $34.41^{\circ} \mathrm{C}$, respectively. And its melting enthalpy and freezing enthalpy separately are $35.46 \mathrm{~J} / \mathrm{g}$ and $32.71 \mathrm{~J} / \mathrm{g}$.

The theoretical enthalpy of samples can be estimated by Eq. 2:

$$
\Delta H_{L A-M A / A C}=\eta \cdot \Delta H_{L A-M A},
$$

where $\Delta H_{L A-M A / A C}, \eta$ and $\Delta H_{L A-M A}$ separately are represent the theoretical enthalpy of CPCMs $(\mathrm{J} / \mathrm{g})$, mass content of PCM in CPCM and pure LA-MA eutectic latent heat $(\mathrm{J} / \mathrm{g})$. It is calculated that the theoretical value is quite different from the DSC test value. This result may be due to the interaction force between the PCM is strengthened so that the part of PCM cannot crystallize freely.

The performance parameters compared with previous experimental studies using fatty acids as energy storage carrier are listed in Table 3, including fusion point, fusion enthalpy and the mass fraction of fatty acids in the CPCMs. It can be found that the LA-MA/AC prepared in this study has a good heat storage capacity under the same support material.

\subsection{TGA dates analysis of LA-MA/AC composites}

The TGA and derivative thermogravimetric (DT) curves of LA-MA/AC composites are shown in Fig. 7 and Fig. 8, respectively. The data of TGA and DT of LA-MA/AC composites are shown in Table 4, which contains the onset decomposition temperature ( $T_{\text {onset }}$ ), the temperature of maximum mass loss rate $\left(T_{\max }\right)$, the final decomposition temperature $\left(T_{\text {end }}\right)$, the maximum weight loss rate $\left(W_{\max }\right)$ and the residual weight at $700{ }^{\circ} \mathrm{C}$. The Fig. 7 and Table 4 indicates that the LA-MA eutectic begins to decomposition at $148.12^{\circ} \mathrm{C}$ and reaches the maximum decomposition rate of $46.34 \% / \mathrm{min}$ at $265.33^{\circ} \mathrm{C}$.

Table 2. DSC date of the LA-MA eutectic and CPCM samples

\begin{tabular}{|l|c|c|c|c|c|c|}
\hline \multirow{2}{*}{ Samples } & \multicolumn{3}{|c|}{ Solid to liquid } & \multicolumn{3}{|c|}{ Liquid to Solid } \\
\cline { 2 - 7 } & $\begin{array}{c}\text { Onset } \\
\text { temperature, }{ }^{\circ} \mathrm{C}\end{array}$ & $\begin{array}{c}\text { Peak } \\
\text { temperature, }{ }^{\circ} \mathrm{C}\end{array}$ & $\begin{array}{c}\text { Enthalpy, } \\
\mathrm{J} \cdot \mathrm{g}^{-1}\end{array}$ & $\begin{array}{c}\text { Onset } \\
\text { temperature, }{ }^{\circ} \mathrm{C}\end{array}$ & $\begin{array}{c}\text { Peak } \\
\text { temperature, }{ }^{\circ} \mathrm{C}\end{array}$ & $\begin{array}{c}\text { Enthalpy, } \\
\mathrm{J} \cdot \mathrm{g}^{-1}\end{array}$ \\
\hline LA-MA eutectic & 32.42 & 38.90 & 152.64 & 33.63 & 30.29 & 148.8 \\
\hline CPCM1 & 34.89 & 38.13 & 21.91 & 34.52 & 32.91 & 19.61 \\
\hline CPCM2 & 34.77 & 38.49 & 35.46 & 34.41 & 32.66 & 32.71 \\
\hline CPCM3 & 34.64 & 38.74 & 47.96 & 34.32 & 32.15 & 45.45 \\
\hline CPCM4 & 34.52 & 38.16 & 61.67 & 34.25 & 32.54 & 56.82 \\
\hline
\end{tabular}

Table 3. Comparison of this study with other literature studies

\begin{tabular}{|c|c|c|c|c|}
\hline CPCMs & Fusion point, ${ }^{\circ} \mathrm{C}$ & Fusion enthalpy, J/g & Mass fraction of PCM, \% & Reference \\
\hline Octanoic-lauric acid/expanded graphite & 3.6 & 132.8 & 93 & [3] \\
\hline Beeswax/multi-walled carbon nanotubes & 59.8 & 91.6 & 80 & [16] \\
\hline Myristic acid/graphite nanoplates & 54.0 & 181 & 99 & [18] \\
\hline Capric-palmitic-stearic acid/ activated carbon & 19.82 & 34.62 & 55 & {$[21]$} \\
\hline LA-MA/AC & 38.49 & 35.46 & 55 & Present study \\
\hline
\end{tabular}




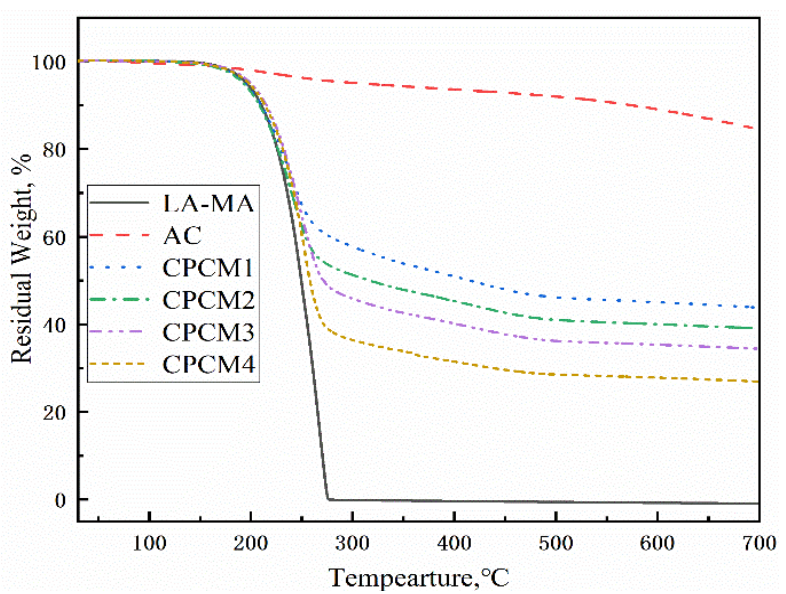

Fig. 7. TGA curves of LA-MA eutectic, CPCM1, СРCM2, CPCM3, CPCM4 and AC.

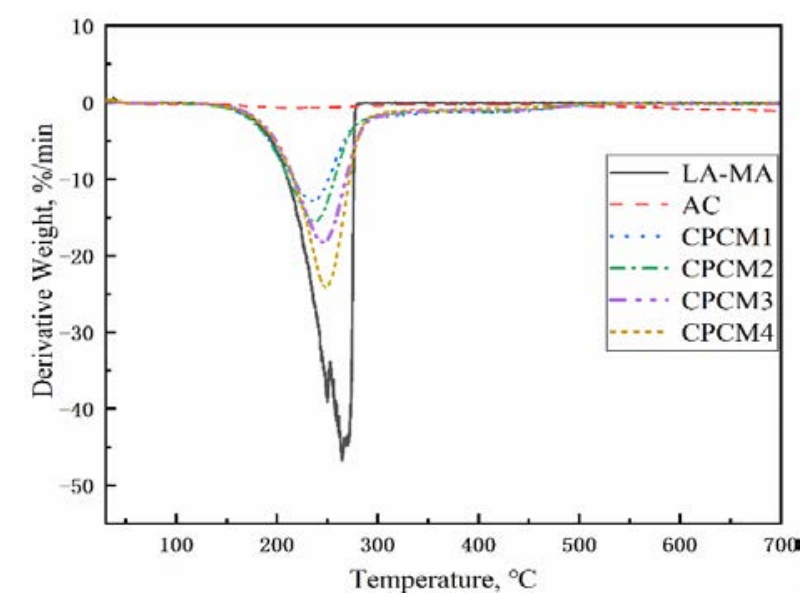

Fig. 8. DT curves of LA-MA eutectic, CPCM1, CPCM2, CPCM3, CPCM4 and AC

CPCM1 to CPCM4 have a similar process of decomposition, the initial decomposition temperature at $134.74^{\circ} \mathrm{C}, 142.87^{\circ} \mathrm{C}$, $140.46^{\circ} \mathrm{C}$, and $135.57^{\circ} \mathrm{C}$, respectively and the maximum decomposition temperature at $235.9^{\circ} \mathrm{C}, 240.97^{\circ} \mathrm{C}, 246.02{ }^{\circ} \mathrm{C}$, and $249.39^{\circ} \mathrm{C}$, respectively. This decomposition temperature is very similar to the decomposition temperature of the LA-MA eutectic, indicating that the main decomposition product is LA-MA eutectic at this temperature. The residual weight of CPCM1, CPCM2, CPCM3, CPCM4 are shown in Table 4 , which are $43.71 \%$, $38.98 \%, 34.34 \%$, and $26.85 \%$, respectively. However, the maximum decomposition rate decreases with the proportion of AC increases, indicating that AC enhances the thermal stability of the eutectic material. The mass loss value is slightly different from the ratio of LA-MA eutectic in composite PCM and Fig. 8 illustrates that AC has almost no mass loss during heating, indicating that it has good thermal stability. The results show that the thermal stability of the LA-MA eutectic is enhanced by adding AC.

\section{CONCLUSIONS}

A new composite was prepared with LA-MA eutectic as the PCM and AC was used as the support material, in which the mass fraction of PCM was $50 \%, 55 \%, 60 \%$ and $65 \%$, respectively. The FT-IR and XRD results show that the composite process of LA-MA eutectic and AC was a simple physical mixing and no new chemical bonds were found. The DSC data and SEM graphs indicates that the optimal composite ratio of LA-MA eutectic to AC is 5.5:4.5, and the fusion and freeze temperature are $34.77^{\circ} \mathrm{C}$ and $34.41^{\circ} \mathrm{C}$, respectively. The difference between fusion temperature and freeze temperature is $0.32{ }^{\circ} \mathrm{C}$. And its melting enthalpy and freezing enthalpy are $35.46 \mathrm{~J} / \mathrm{g}$ and $32.71 \mathrm{~J} / \mathrm{g}$, respectively. This material can be applied for energy storage in solar energy storage system.

\section{Acknowledements}

This study was supported by the Nanchang University Postgraduate Innovation Special Fund (NO: CX2019066), Jiangxi Provincial Science and Technology Support Plan Project "Research on Energy Storage Solar-Air Dual Heat Source Compound Heat Pump System” (20112BBE50031).

\section{REFERENCES}

1. Aftab, W, Huang, X.Y., Wu, W.H., Liang, Z.B., Mahmood, A., Zou, R.Q. Nanoconfined Phase Change Materials for Thermal Energy Applications Energy and Environmental Science 11 (6) 2018: pp. 1392-1424. https://doi.org/10.1039/C7EE03587J

2. Rezaie, A.B., Montazer, M. In Situ Incorporation and Loading of Copper Nanoparticles into a Palmitic-lauric phase-change Material on Polyester Fibers Journal of Applied Polymer Science 136 (3) 2019: pp. 46951. https://doi.org/10.1002/app.46951

3. Li, Y.Y., Zhang, X.L., Munyalo, J.M., Tian, Z., Ji, J. Preparation and Thermophysical Properties of Low Temperature Composite Phase Change Material Octanoiclauric Acid/Expanded Graphite Journal of Molecular Liquids 277 2019: pp. 577-583. https://doi.org/10.1016/j.molliq.2018.12.111

4. Lee, J., Wi, S., Yun, B.Y., Chang, S.J., Kim, S. Thermal and Characteristic Analysis of Shape-stabilization Phase Change Materials by Advanced Vacuum Impregnation Method Using Carbon-based Materials Journal of Industrial and Engineering Chemistry 70 2019: pp. 281-289. https://doi.org/10.1016/j.jiec.2018.10.028

5. Jiang, X., Luo, R.L., Peng, F.F., Akiyama, T., Wang, S.F. Synthesis, Characterization and Thermal Properties of Paraffin Microcapsules Modified with Nano- $\mathrm{Al}_{2} \mathrm{O}_{3}$ Applied Energy 137 2015: pp. 731-737. https://doi.org/10.1016/j.apenergy.2014.09.028

Table 4. TGA date of the LA-MA eutectic, CPCM1, CPCM2, CPCM3, CPCM4 and AC

\begin{tabular}{|l|c|c|c|c|c|}
\hline Samples & $T_{\text {onset }}{ }^{\circ} \mathrm{C}$ & $T_{\max },{ }^{\circ} \mathrm{C}$ & $T_{\text {end, }}{ }^{\circ} \mathrm{C}$ & $W_{\max }, \% / \min$ & Residual weight, $\%$ at $700{ }^{\circ} \mathrm{C}$ \\
\hline LA-MA eutectic & 148.12 & 265.33 & 281.11 & 46.34 & 0 \\
\hline CPCM1 & 134.74 & 235.92 & 299.65 & 12.86 & 43.71 \\
\hline CPCM2 & 142.87 & 240.97 & 304.55 & 15.38 & 38.98 \\
\hline CPCM3 & 140.46 & 246.02 & 307.92 & 18.08 & 34.34 \\
\hline CPCM4 & 135.57 & 249.39 & 307.16 & $24.03 \mathrm{~m}$ & 26.85 \\
\hline AC & 199.07 & - & - & - & 84.52 \\
\hline
\end{tabular}


6. Lin, Y.X., Zhu, C.Q., Alva, G., Fang, G.Y. Palmitic Acid/Polyvinyl Butyral/Expanded Graphite Composites as Form-stable Phase Change Materials for Solar Thermal Energy Storage Applied Energy 228 2018: pp. $1801-1809$.

https://doi.org/10.1016/j.apenergy.2018.07.068

7. Kumar, R., Vyas, S., Dixit, A. Fatty Acids/1-Dodecanol Binary Eutectic Phase Change Materials for Low Temperature Solar Thermal Applications: Design, Development and Thermal Analysis Solar Energy 155 2017: pp. $1373-1379$. https://doi.org/10.1016/j.solener.2017.07.082

8. Hussain, A., Tso, C.Y., Chao, C.Y. Experimental Investigation of a Passive Thermal Management System for High-powered Lithium Ion Batteries Using Nickel Foamparaffin Composite Energy 115 (115) 2016: pp. 209-218. https://doi.org/10.1016/j.energy.2016.09.008

9. Samimi, F., Babapoor, A., Azizi, M., Karimi, G. Thermal Management Analysis of A Li-ion Battery Cell Using Phase Change Material Loaded with Carbon Fibers Energy 96 2016: pp. 355-371.

https://doi.org/10.1016/j.energy.2015.12.064

10. Shon, J., Kim, H., Lee, K. Improved Heat Storage Rate for An Automobile Coolant Waste Heat Recovery System Using Phase-change Material in a Fin-tube Heat Exchanger Applied Energy 113 2014: pp. 680-689. https://doi.org/10.1016/j.apenergy.2013.07.049

11. Moldgy, A., Parameshwaran, R. Study on Thermal Energy Storage Properties of Organic Phase Change Material for Waste Heat Recovery Applications Materials Today: Proceedings 5 (8) 2018: pp. 16840-16848. https://doi.org/10.1016/j.matpr.2018.05.137

12. Parameshwaran, R., Harikrishnan, S., Kalaiselvam, S. Energy Efficient PCM-based Variable Air Volume Air Conditioning System for Modern Buildings Energy and Buildings 42 (8) 2010: pp. 1353-1360.

https://doi.org/10.1016/j.enbuild.2010.03.004

13. Yang, X.J., Yuan, Y.P., Zhang, N., Cao, X.L., Liu, C. Preparation and Properties of Myristic-palmitic-stearic Acid/Expanded Graphite Composites as Phase Change Materials for Energy Storage Solar Energy 99 2014: pp. 259-266.

https://doi.org/10.1016/j.solener.2013.11.021

14. Kim, D., Jung, J., Kim, Y., Lee, M., Seo, J., Khan, S.B. Structure and Thermal Properties of Octadecane/Expanded Graphite Composites as Shape-stabilized Phase Change Materials International Journal of Heat and Mass Transfer 95 2016: pp. 735-741.

https://doi.org/10.1016/j.ijheatmasstransfer.2015.12.049

15. Li, Y.Y., Zhang, X.L., Munyalo, J.M., Tian, T. Preparation and Thermophysical Properties of Low Temperature Composite Phase Change Material Octanoic-lauric acid/Expanded Graphite Journal of Molecular Liquids 277 2019: pp. 577-583.

https://doi.org/10.1016/j.molliq.2018.12.111

16. Putra, N., Rawi, S., Amin, M., Kusrini, E., Kosasih, E.A., Mahlia, T.M.I. Preparation of Beeswax/Multi-walled Carbon Nanotubes as Novel Shape-stable Nanocomposite Phase-change Material for Thermal Energy Storage Journal of Energy Storage 21 2019: pp. 32-39. https://doi.org/10.1016/j.est.2018.11.007

17. Feng, Y.H., Wei, R.Z., Huang, Z., Zhang, X.X., Wang, G. Thermal Properties of Lauric Acid Filled in Carbon Nanotubes as Shape-stabilized Phase Change Materials Physical Chemistry Chemical Physics $20(11)$
2018: pp. $7772-7780$.

https://doi.org/10.1039/C7CP08557E

18. Liu, C.Z., $\quad$ Luo, C.Y., $\quad$ Xu, T.T., Lv, P.Z., Rao, Z.H. Experimental Study on the Thermal Performance of Capric Acid-myristyl Alcohol/Expanded Perlite Composite Phase Change Materials for Thermal Energy Storage Solar Energy 191 2019: pp. 585-595. https://doi.org/10.1016/j.solener.2019.09.049

19. Hasanabadi, S., Sadrameli, S.M., Sami, S. Preparation, Characterization and Thermal Properties of Surface-modified Expanded Perlite/Paraffin as a Form-stable Phase Change Composite in Concrete Journal of Thermal Analysis and Calorimetry 2020: pp. 1-9. https://doi.org/10.1007/s10973-020-09440-1

20. Hu, Z.J., Wang, C.M., Jia, W.B., Li, Z.Y., Cai, Z.Y. Preparation and Thermal Properties of 1-Hexadecanolpalmitic Acid Eutectic Mixture/Activated Carbon Composite Phase Change Material for Thermal Energy Storage ChemistrySelect 4 (1) 2019: pp. 222-227. https://doi.org/10.1002/slct.201801773

21. Yuan, Y.P., Li, T.Y., Zhang, N., Cao, X.L., Yang, X.J. Investigation on Thermal Properties of Capric-palmiticstearic Acid/Activated Carbon Composite Phase Change Materials for High-temperature Cooling Application Journal of Thermal Analysis and Calorimetry $124(2)$ 2016: pp. $881-888$. https://doi.org/10.1007/s10973-015-5173-0

22. Feng, L.L., Zheng, J., Yang, H.Z., Guo, Y.L., Li, W., Li, X.G. Preparation and Characterization of Polyethylene Glycol/Active Carbon Composites as Shape-stabilized Phase Change Materials Solar Energy Materials and Solar Cells 95 (2) 2011: pp. 644-650. https://doi.org/10.1016/j.solmat.2010.09.033

23. Zhang, J.S., Wang, Z.M., Li, X.Q., Wu, X. Novel Composite Phase Change Materials with Enhancement of Light-thermal Conversion, Thermal Conductivity and Thermal Storage Capacity Solar Energy 196 2020: pp. 419-426. https://doi.org/10.1016/j.solener.2019.12.041

24. Ince, Ş., Seki, Y., Ezan, M.A., Turgut, A., Erek, A. Thermal Properties of Myristic Acid/Graphite Nanoplates Composite Phase Change Materials Renewable Energy 75 2015: pp. $243-248$. https://doi.org/10.1016/j.renene.2014.09.053

25. Su, D., Jia, Y.T., Alva, G., $\quad$ Tang, F., Fang, G.Y. Preparation and Thermal Properties of N-octadecane/Stearic Acid Eutectic Mixtures with Hexagonal Boron Nitride as Phase Change Materials for Thermal Energy Storage Energy \& buildings 131 2016: pp. 35-41. https://doi.org/10.1016/j.enbuild.2016.09.022

26. Alva, G., Huang, X., Liu, L.K., Fang, G.Y. Synthesis and Characterization of Microencapsulated Myristic Acid-Palmitic Acid Eutectic Mixture as Phase Change Material for Thermal Energy Storage Applied Energy 203 2017: pp. 677-685. https://doi.org/10.1016/j.apenergy.2017.06.082

27. Luo, Z.G., Zhang, H., Gao, X.N., Xu, T., Fang, Y.T., Zhang, Z.G. Fabrication and Characterization of Form-stable Capric-palmitic-stearic Acid Ternary Eutectic Mixture/Nano$\mathrm{SiO}_{2}$ Composite Phase Change Material Energy and Buildings 147 2017: pp. 41-46. https://doi.org/10.1016/j.enbuild.2017.04.005

28. Tang, Y.J., Su, D., Huang, X., Alva, G., Fang, G.Y. Synthesis and Thermal Properties of the MA/HDPE Composites with Nano-additives as Form-stable PCM with 
Improved Thermal Conductivity

2016: pp. 116-129.

https://doi.org/10.1016/j.apenergy.2016.07.106

29. Ismar, E., Sarac, A.S. Electrospun Polyacrylonitrile-lauric Acid Composite Nanofiber Webs as A Thermal Energy Storage Material Journal of Engineered Fibers and Fabrics 14 2019: pp. 1-6.

https://doi.org/10.1177\%2F1558925018824890
30. Li, C.C., Wang, M.F., $\quad$ Xie, B.S., $\quad$ Ma, H., Chen, J. Enhanced Properties of Diatomite-based Composite Phase Change Materials for Thermal Energy Storage Renewable Energy 147 2020: pp. 265-274.

https://doi.org/10.1016/j.renene.2019.09.001

(C) Chen et al. 2022 Open Access This article is distributed under the terms of the Creative Commons Attribution 4.0 International License (http://creativecommons.org/licenses/by/4.0/), which permits unrestricted use, distribution, and reproduction in any medium provided you give appropriate credit to the original author(s) and the source, provide a link to the Creative Commons license, and indicate if changes were made. 